\title{
Morphological changes in temporomandibular joint dysfunction and effectiveness of different treatment methods
}

\author{
Fatma Duman $^{1}$ (D) , Aynur Emine Çiçekçibaşı ${ }^{2}$ (D), Nesrin Atçı ${ }^{3}$ (D), Fatma Öztürk ${ }^{3}$ (D), \\ Bircan Yücekaya $^{4}$ (D), Esra Doğru Hüzmeli ${ }^{4}$ (D), İbrahim Damlar ${ }^{5}$ (D) \\ ${ }^{\prime}$ Department of Anatomy, Tayfur Ata Sökmen School of Medicine, Mustafa Kemal University, Hatay, Turkey \\ ${ }^{2}$ Department of Anatomy, Meram School of Medicine, Necmettin Erbakan University, Konya, Turkey \\ ${ }^{3}$ Department of Radiology, Tayfur Ata Sökmen School of Medicine, Mustafa Kemal University, Hatay, Turkey \\ ${ }^{4}$ Department of Physical Therapy and Rehabilitation, Tayfur Ata Sökmen School of Medicine, Mustafa Kemal University, Hatay, Turkey \\ ${ }^{5}$ Department of Oral and Maxillofacial Surgery, School of Dentistry, Mustafa Kemal University Hatay, Turkey
}

\begin{abstract}
Objectives: Temporomandibular joint dysfunction (TMD) results in changes in anatomical structures. The aim of this study was to examine the morphological changes using magnetic resonance imaging (MRI) and evaluate the effectiveness of different treatment methods in patients with TMD.

Methods: 34 TMD patients (18-62 years of age) were randomly divided into two treatment groups. Group A ( $n=18$ ) was subjected to dry needling (DN) and mobilization for 10 sessions, Group B $(n=16)$ was instructed to use occlusal splint with home exercises for one month. The control group included MRIs of 17 healthy adults that were randomly selected from the archives of Radiology Department of Mustafa Kemal University. The length and width of the masseter, lateral and medial pterygoid muscles and the depth of the mandibular fossa were measured and mandibular condyle types were recorded. Range of motion of each temporomandibular joint was evaluated in pre- and post-treatment periods to test the effectiveness of the treatment methods.

Results: The size of the masticatory muscles in TMD group was significantly smaller than the control group ( $p<0.05)$. The depth of the mandibular fossa was significantly shallower in the TMD group $(p<0.05)$. The most commonly encountered condylar shape was convex in the TMD group (63.6\%), but flat (58.8\%) in the control group. No statistically significant relationship was observed between condyle type and fossa depth ( $p>0.05$ ). However, the fossa depth showed a significant correlation with muscle size $(p<0.05)$ and this correlation decreased with dysfunction. Dry needling and mobilization significantly decreased pain and increased mandibular movements ( $p<0.05$ ); however, there was no significant change for Group B.

Conclusion: The anatomical structures associated with the temporomandibular joint seems to be affected in patients with TMD. We suggest that the limited movement of the temporomandibular joint may cause atrophy of the masticatory muscles, affecting the range of motion of the joint. Dry needling and mobilization techniques might be a more effective alternative than occlusal splint in the treatment of TMD.
\end{abstract}

Keywords: mandibular fossa; masticatory muscles; temporomandibular joint dysfunction

Anatomy 2020;14(2):102-110 @2020 Turkish Society of Anatomy and Clinical Anatomy (TSACA)

\section{Introduction}

Temporomandibular dysfunction (TMD) is an important public health problem, resulting in pain and disability. This complicated and multifactorial condition affects the masticatory muscles, the temporomandibular joint (TMJ) and associated structures. ${ }^{[1,2]}$ Trauma, habitual activity, various types of arthritis and occlusal variations are common factors that increase the risk of developing TMD. Despite the exact etiology of TMD is unknown yet, genetic, anatomic and hormonal factors predispose the joint to dysfunction. $^{[3]}$ 
TMJ is a unique and complex joint of the body on account of its anatomical and functional features. ${ }^{[4]}$ TMJ is an ellipsoid variety with two synovial joint cavities joined by a single articular surface on mandible. It can be considered as a bicondylar articulation that cannot move independently. ${ }^{[5]}$ The articular surfaces consists of the mandibular fossa, the articular tubercle and the condylar process of the mandible. There is a fibrocartilagenous disc between the mandibular fossa and the condyle creating a superior and an inferior compartment allowing protrusion and retrusion on the superior compartment and elevation and depression on the inferior compartment. This disc allows the condyle to move easily and acts as a cushion to absorb stress during the jaw movements. The masticatory muscles surrounding the joint are strong muscles that control the movement of the jaw, contracting and relaxing in harmony to allow the jaw function properly. ${ }^{[5,6]}$

TMD is associated with an abnormal positional relationship between the articular disc, mandibular condyle, articular tubercle and mandibular fossa. ${ }^{[7]}$ Condylar positional changes following intracapsular alterations and the alterations in the condyle shape and morphometry affect the functional properties of the TMJ ${ }^{[8]}$ A steep slope of the articular tubercle and the slope of the mandibular fossa are predisposing factors to this disorder. ${ }^{[9]}$ One of the most frequent cause of TMD is disc displacement (DD) which is defined as an abnormal position and/or malfunction of the articular disc. ${ }^{[10]}$ Besides that, masticatory muscles are commonly affected in TMD. Unilateral chewing or possible sleep bruxism may lead to chronic local muscular contracture, inflammation, and localized muscular hypo or hypertrophy, which may cause myofascial pain. ${ }^{[1]}$

Previous studies suggest a variety of treatment options such as occlusal splint, physical therapy, dry needling, exercises, botox and surgery for TMD.$^{[12-14]}$ An occlusal splint is the most preferred treatment option. Besides it mechanic action, splints have been shown to help in regulating blood circulation of the TMJ ${ }^{[15]}$ Other treatment options to increase the blood circulation are physical therapy (exercises), mobilization and dry needling. Passive and active stretching exercises, isometric tension and relaxation exercises are helpful for reducing limitation in jaw movements. Dry needling and mobilization are suggested for decreasing local muscle tenderness and help to gain full range of movements, respectively. ${ }^{[16-18]}$

The present study was carried out to evaluate the role of different treatment methods (occlusal splint, exercise, dry needling and mobilization) in TMD by examining the internal derangement of TMJ and changes in the size of the mastication muscles with magnetic resonance imaging (MRI); and investigating the effect of these treatment methods on the range of motion of TMJ.

\section{Materials and Methods}

The study included 34 TMD patients (27 females, 7 males) with a mean age of $29.44 \pm 12.97$ (range: 18-62) years. The patients were randomly divided into two treatment groups. Group A (13 females, 5 males) underwent dry needling (DN) and mobilization. Group B (14 females, 2 males) were instructed to use the splint during sleep to do certain home exercises to increase the strength and stretching of masticatory muscles. MRI images of the patients were taken before treatment. For comparison of MRI measurements, a control group was added as Group C including MR images of 17 healthy individuals with a mean age of $32.82 \pm 11.99$ (range: $18-56$ ) years without any pathological changes in TMJ. The images were randomly selected from the archives of Radiology Department of Tayfur Ata Sökmen School of Medicine, Mustafa Kemal University. The study was approved by Medical Ethics Committee of Mustafa Kemal University (No: 4298783/050-41) and consent was obtained from all participants in accordance with the principles of the Declaration of Helsinki.

Inclusion criteria of the TMD patients included being older than 18 years of age and having limited mouth opening. The exclusion criteria were the presence of condylar hyperplasia, rheumatoid arthritis, congenital craniofacial syndrome, benign or malignant parotid disease, rhabdomyoma and lymphangioma. Individuals who were disabled, pregnant, mentally retarded and with acute trauma were excluded from the study. Treatment procedures were as follows. Group A: Patients were subjected to 3 weeks of dry needling and mobilization (totally 10 sessions). Sterile stainless $13 \mathrm{~mm}$ long, $0.2 \mathrm{~mm}$ thick steel acupuncture needles with a plastic cylindrical guide have been used for $\mathrm{DN}$. The needle was applied uni- or bilaterally after cleaning of the treatment area with $90 \%$ alcohol. The needle was inserted perpendicularly through the active trigger points of the muscles. In addition to DN, massage therapy consisting of synchronized gliding and kneading with medium pressure (alternately on the masseter, temporal and medial pterygoid muscles which totally took 10 minutes) and TMJ mobilization (caudal and ventro-caudal traction, ventral and mediolateral translation) were performed.

Group B: Patients instructed to use occlusal splint during sleeping for one month. A soft occlusal splint was manufactured from a $3 \mathrm{~mm}$-thick, soft polyvinyl sheet which was adapted to a maxillary cast. Besides to splint, an exercise program was given consisting of slow active mouth opening and closing exercises, isometric mouth exercises and mouth stretching exercises. Each exercise was performed for 5 seconds with 10 repetitions, twice a day for 4 weeks.

The clinical evaluation of the patients was done by measuring certain parameters to determine limitation of 
mandibular movement before and after treatment. A ruler was used to measure mandibular depression (maximum mouth opening), protrusion, retraction and lateral deviations on each side. Distance between superior and inferior incisive teeth's midpoint was taken as reference for this measurement. ${ }^{[2]}$

MRI images were obtained with a $1.5 \mathrm{~T}$ MR imaging system (Philips Achieva; Philips Medical Systems, Best, the Netherlands) with a surface array coil. Proton density weighted (PDW) turbo spin echo sequences were taken in the sagittal plane in the closed-opened mouth position and in the coronal-sagittal plane in the closed mouth position. T2-weighted (T2W) turbo spin echo sequences were taken in the sagittal plane in the closed-opened mouth position. The scan parameters for PDW were; time repetition (TR) / time echo (TE) $1500 / 30$, matrix of $224 \times 153$. The scan parameters for T2W were; TR/TE 1500/30, matrix of $224 \times 153$. Slice thickness was $3 \mathrm{~mm}$, section gap was $0.3 \mathrm{~mm}$, and a field of view (FOV) of almost $140 \mathrm{~mm}$ were for all sequences. Two radiologists interpreted the MRI sequences in the digital imaging in medicine viewer software-OsiriX (Pixmeo Labs, Geneva, Switzerland). The length and width of masseter, medial pterygoid (PTM) and the superior and inferior heads of lateral pterygoid (PTL) muscles and the depth of mandibular fossa was measured. Additionally, the type of mandibular condyle was evaluated.

The masseter was measured in the sagittal T2W sequence in open mouth position (Figure 1), the superior

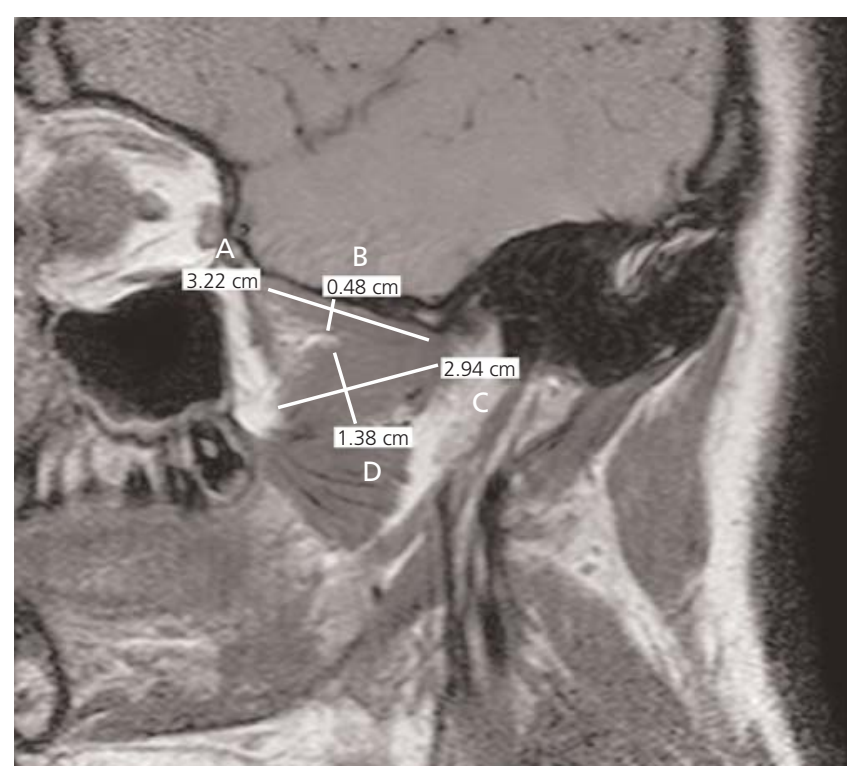

Figure 2. Sagittal closed-mouth T2W TSE MRI. Measurement of the length (A) and width (B) of the superior head of lateral pterygoid muscle; length (C) and width (D) of the inferior head of lateral pterygoid muscle.

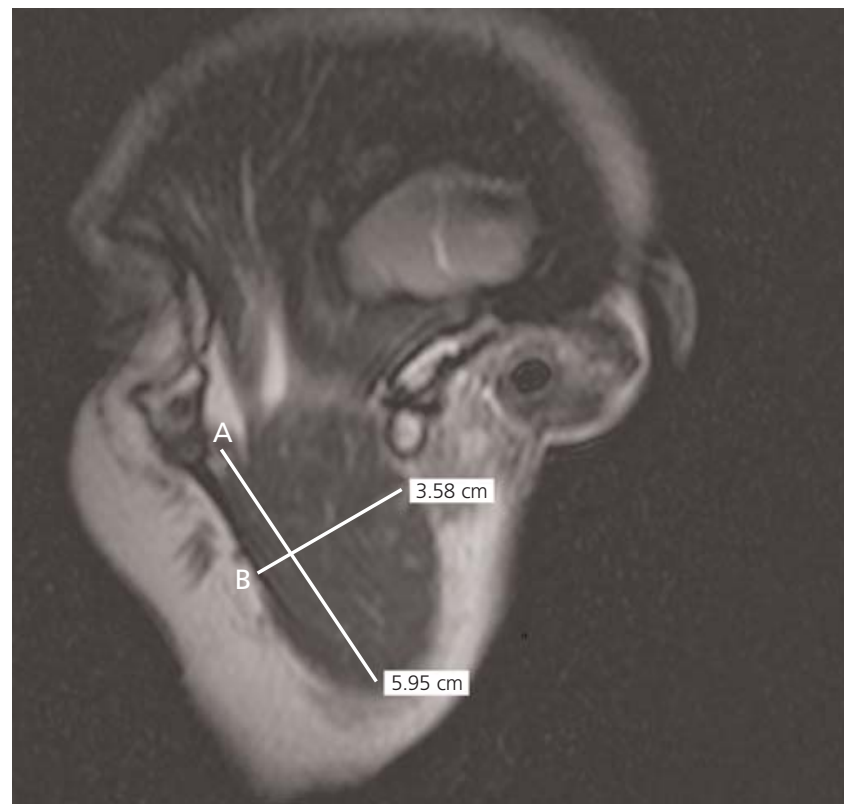

Figure 1. Sagittal open-mouth T2W TSE MRI. Measurement of the length $(A)$ and width (B) of the masseter muscle.

and inferior heads of lateral pterygoid muscle in the sagittal PDW sequence in closed mouth position (Figure 2) and the medial pterygoid muscle in the coronal PDW sequence in closed mouth position (Figure 3). The length between origin-insertion of the muscle was measured in each slice and the longest distance is considered as the

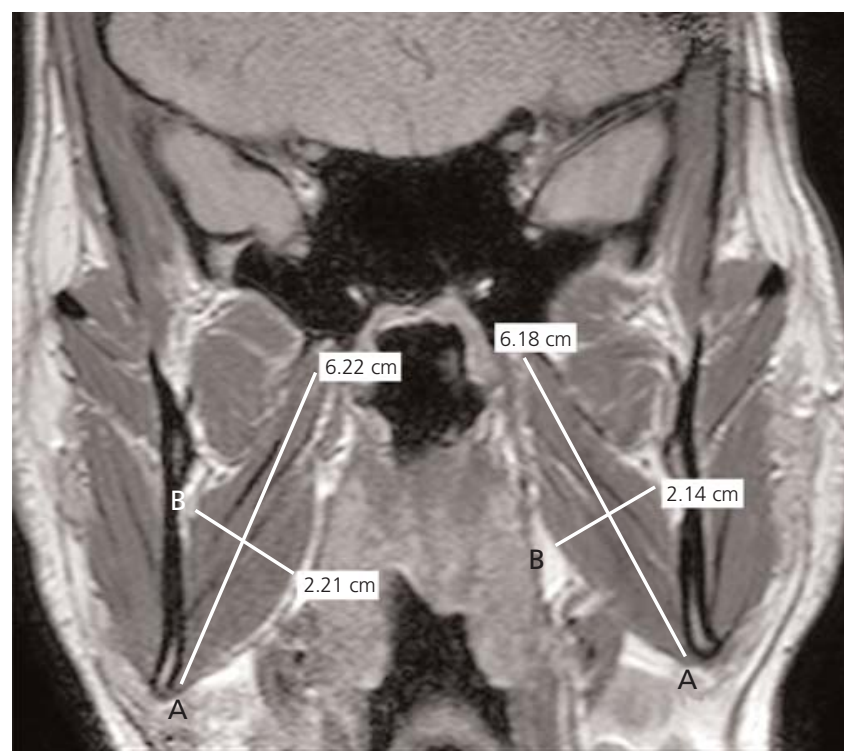

Figure 3. Coronal closed-mouth PDW TSE MRI. Measurement of the length $(\mathrm{A})$ and width $(\mathrm{B})$ of the medial pterygoid muscle. 

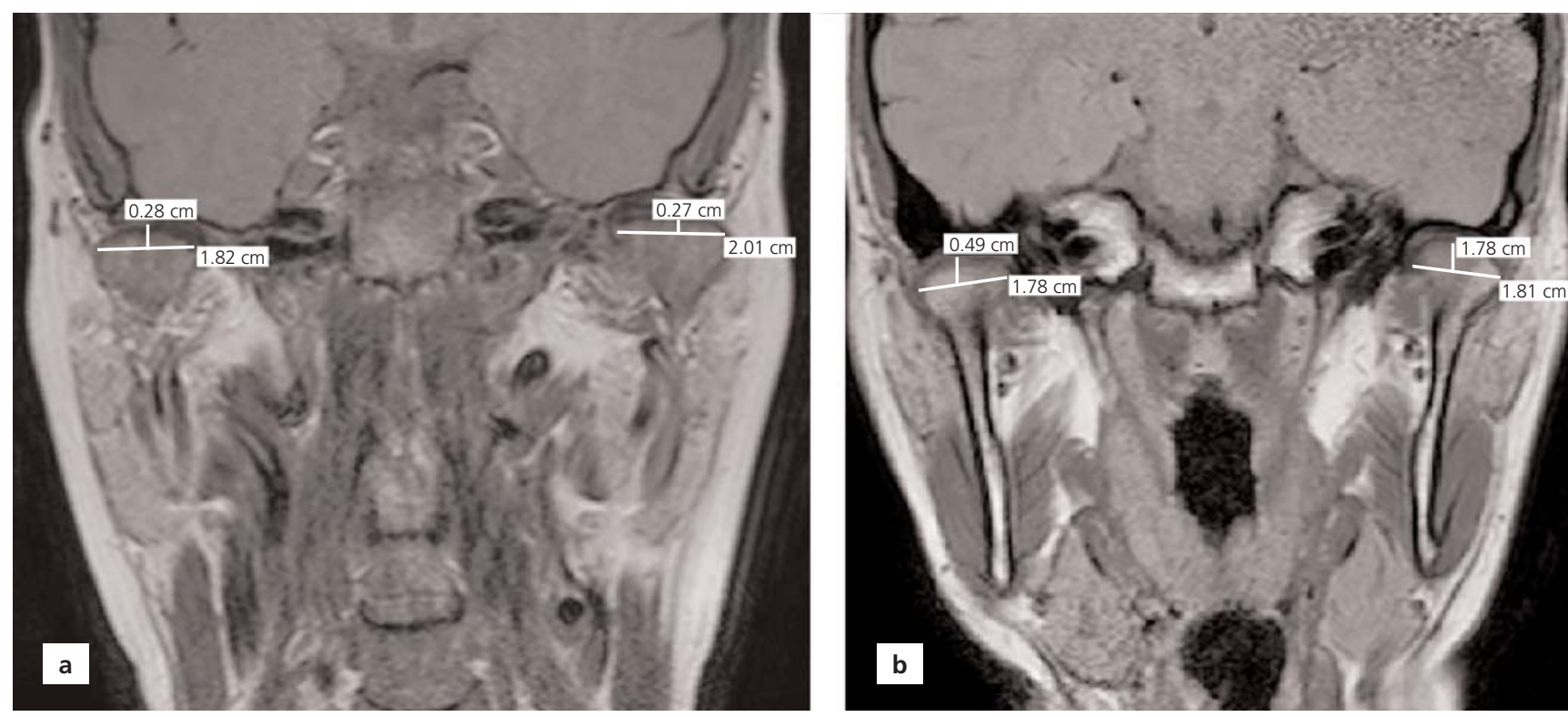

Figure 4. Coronal closed-mouth PDW TSE MRI showing the shape of mandibular condyle. Flat type (a) and convex type (b) condyle.

length of the muscle. Width of muscles was measured from the widest point in the same slice. ${ }^{[19]}$

Mandibular condyle was classified into four types according to its shape as; convex, flat, angular and round. ${ }^{[2-22]}$ The mandibular condyle was evaluated in the coronal PDW sequence in close mouth position (Figure $4)$.

The depth of mandibular fossa was measured between the superior edge of mandibular fossa and the most inferi-

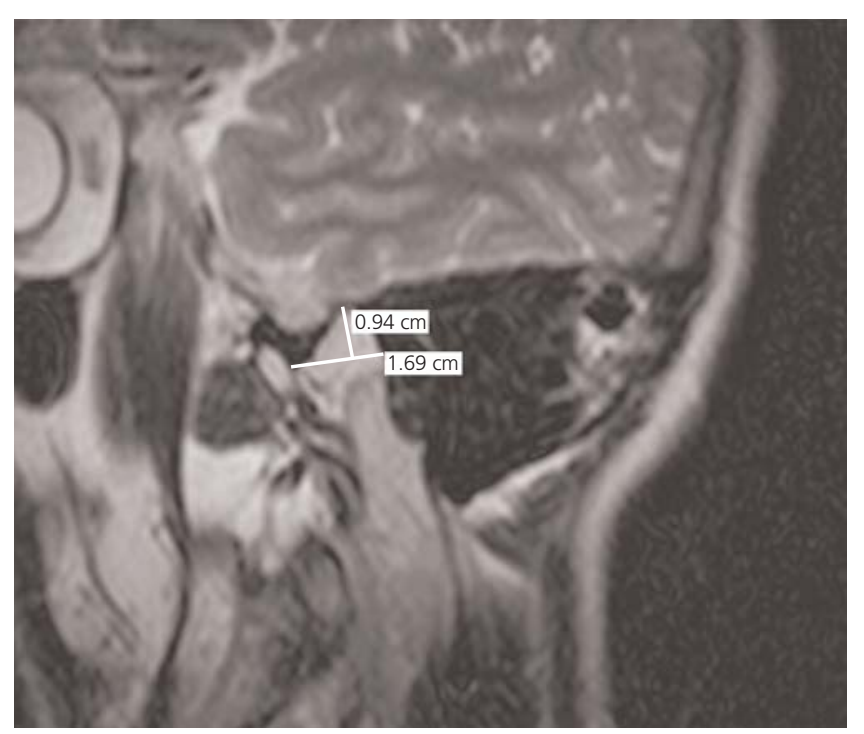

Figure 5. Sagittal open-mouth T2W TSE MRI. Measurement of the depth of the mandibular fossa. or edge of articular tubercle in the sagittal T2W sequence in open mouth position (Figure 5)..$^{[2]]}$

Statistical analyses were performed using the IBM SPSS Statistics for Windows (Version 20.0, Armonk, NY, USA). Normality of the data was tested with the KolmogorovSmirnov/Shapiro-Wilk tests. Mann-Whitney $U$ test is used to compare differences between the groups when the data did not normally distributed. Nominal data were compared using a Chi-square test. The Wilcoxon signed-rank test was used to compare the change in mandibular movements between pre-treatment and post-treatment period. Correlations between depth of mandibular fossa, condyle type, size of masticatory muscles were calculated using Spearman's test rank correlation coefficients. A $\mathrm{p} \leq 0.05$ was considered as statistically significant.

\section{Results}

The patients were randomly divided into two different groups. However, bilateral dysfunction was more than unilateral in Group A; in Group B, left side was more affected than the right side $(\mathrm{p}<0.05)$ Table $\mathbf{1})$.

The length of the masseter, superior head of lateral pterygoid and medial pterygoid muscles on both sides; the width of the masseter and medial pterygoid muscles on the left side in TMD group was significantly shorter than control group $(\mathrm{p}<0.05)($ Table 2$)$.

Convex type of condyle was more common $(63.6 \%)$ in TMD group; however, flat type was seen more $(58.8 \%)$ in 
Table 1

Clinical examination outcomes of the TMD patients.

\begin{tabular}{|c|c|c|c|c|c|c|c|}
\hline & & \multicolumn{2}{|c|}{ Group A } & \multicolumn{2}{|c|}{ Group B } & \multirow[b]{2}{*}{$\chi^{2}$} & \multirow[b]{2}{*}{ p } \\
\hline & & $\mathrm{n}$ & $\%$ & $\mathbf{n}$ & $\%$ & & \\
\hline Female & & 13 & 72.2 & 14 & 87.5 & - & 0.405 \\
\hline Male & & 5 & 27.8 & 2 & 12.5 & & \\
\hline \multirow[t]{3}{*}{ Side of dysfunction } & Right & 7 & 38.9 & 2 & 12.5 & 6.633 & $0.040^{*}$ \\
\hline & Left & 2 & 11.1 & 8 & 50.0 & & \\
\hline & Bilateral & 9 & 50.0 & 6 & 37.5 & & \\
\hline
\end{tabular}

${ }^{*} \mathrm{p}<0.05$

control group. There was no significant difference between TMD and control group regarding the condyle type (Table 3). The angular type was seen only in one individual in TMD group, so it was not included in the analysis.
Depth of the mandibular fossa in TMD group was significantly shallower than the control group in both sides $(p<0.05)$ (Table 4). The condyle was of convex type in the patient with deepest mandibular fossa $(9.67 \mathrm{~mm})$ and of flat type with the shallowest one $(3.33 \mathrm{~mm})$. However,

Table 2

Length and width of masticatory muscles $(\mathrm{cm})$ and differences between TMD and control groups.

\begin{tabular}{|c|c|c|c|c|c|c|}
\hline & & & $\begin{array}{l}\text { TMD group } \\
\text { (mean } \pm S D)\end{array}$ & $\begin{array}{l}\text { Control group } \\
(\text { mean } \pm \text { SD) }\end{array}$ & $\mathbf{z}$ & $\mathbf{p}$ \\
\hline \multirow[t]{4}{*}{ Masseter } & \multirow[t]{2}{*}{ Length } & Right & $5.90 \pm 1.248$ & $6.79 \pm 0.492$ & -3.529 & 0.000 * \\
\hline & & Left & $5.92 \pm 1.237$ & $6.86 \pm 0.698$ & -3.676 & 0.000 * \\
\hline & \multirow[t]{2}{*}{ Width } & Right & $3.19 \pm 0.729$ & $3.54 \pm 0.332$ & -1.838 & 0.066 \\
\hline & & Left & $3.10 \pm 0.751$ & $3.67 \pm 0.366$ & -3.235 & 0.001 * \\
\hline \multirow[t]{4}{*}{ Superior LP } & \multirow[t]{2}{*}{ Length } & Right & $2.69 \pm 0.251$ & $3.14 \pm 0.539$ & -3.539 & 0.000 * \\
\hline & & Left & $2.68 \pm 0.324$ & $2.94 \pm 0.278$ & -2.628 & 0.009 * \\
\hline & \multirow[t]{2}{*}{ Width } & Right & $0.65 \pm 0.213$ & $0.70 \pm 0.193$ & -0.785 & 0.432 \\
\hline & & Left & $0.67 \pm 0.193$ & $0.72 \pm 0.184$ & -0.876 & 0.381 \\
\hline \multirow[t]{4}{*}{ Inferior LP } & \multirow[t]{2}{*}{ Length } & Right & $3.20 \pm 0.379$ & $3.30 \pm 0.298$ & -0.649 & 0.517 \\
\hline & & Left & $3.12 \pm 0.267$ & $3.28 \pm 0.288$ & -1.752 & 0.080 \\
\hline & \multirow[t]{2}{*}{ Width } & Right & $1.55 \pm 0.228$ & $1.55 \pm 0.170$ & -0.148 & 0.882 \\
\hline & & Left & $1.50 \pm 0.254$ & $1.62 \pm 0.210$ & -1.604 & 0.109 \\
\hline \multirow[t]{4}{*}{ MP } & \multirow[t]{2}{*}{ Length } & Right & $3.71 \pm 1.980$ & $5.30 \pm 0.554$ & -4.055 & 0.000 * \\
\hline & & Left & $3.69 \pm 1.966$ & $5.42 \pm 0.559$ & -4.238 & 0.000 * \\
\hline & \multirow[t]{2}{*}{ Width } & Right & $1.17 \pm 0.645$ & $1.52 \pm 0.245$ & -1.754 & 0.079 \\
\hline & & Left & $1.18 \pm 0.649$ & $1.57 \pm 0.274$ & -2.096 & 0.036 * \\
\hline
\end{tabular}

Mann-Whitney U test, ${ }^{*} \mathrm{p}<0.05$. Inferior LP: inferior head of lateral pterygoid; MP: medial pterygoid; Superior LP: superior head of lateral pterygoid.

Table 3

Types of the mandibular condyle.

\begin{tabular}{|c|c|c|c|c|c|c|c|}
\hline & & \multicolumn{2}{|c|}{ TMD group } & \multicolumn{2}{|c|}{ Control group } & \multirow[b]{2}{*}{$\chi^{2}$} & \multirow[b]{2}{*}{ p } \\
\hline & & $\mathrm{n}$ & $\%$ & $\mathbf{n}$ & $\%$ & & \\
\hline \multirow[t]{3}{*}{ Mandibular condyle type } & & & & & & 2.297 & 0.130 \\
\hline & Flat & 12 & 36.4 & 10 & 58.8 & & \\
\hline & Convex & 21 & 63.6 & 7 & 41.2 & & \\
\hline Total & 33 & 100.0 & 17 & 100.0 & & & \\
\hline
\end{tabular}

Chi-square test. 
there was no statistically significant correlation between the depth of mandibular fossa and the condyle type $(p>0.05)$. In addition to this, there was a positive correlation between depth of the mandibular fossa and size of the masticatory muscles in both groups $(\mathrm{p}<0.05)$. Nevertheless in the TMD group, depth of the mandibular fossa was correlated only with the length of right and left masseter and the length of right superior part of lateral pterygoid $(\mathrm{p}<0.05)$ (Table 5).

The pre- and post-treatment measurements of range of motion of the joint showed that the range of motion significantly increased in Group A $(\mathrm{p}<0.05)$ (Table 6).

\section{Discussion}

The results of the present study showed that the size of the masticatory muscles was smaller and the depth of mandibular fossa was shallower in patients with TMD. Additionally, the common mandibular condyle shape in TMD patients was of convex type. Clinical evaluation showed that dry needling and mobilization were more effective in increasing the range of motion of the joint than use of occlusal splint and home exercises.

Previously published studies reported that an unstable occlusion could lead to structural changes in TMJ. ${ }^{[3,6,9,21,22]}$ Arnett et al. ${ }^{[23]}$ stated that the occlusion problems causes changing of the mandibular condyle and
Table 4

Depth of the mandibular fossa $(\mathrm{mm})$.

\begin{tabular}{lllcc} 
& $\begin{array}{c}\text { TMD group } \\
(\mathbf{m e a n} \pm \text { SD) }\end{array}$ & $\begin{array}{c}\text { Control group } \\
(\text { mean } \pm \text { SD) }\end{array}$ & $\mathbf{z}$ & $\mathbf{p}$ \\
\hline Right & $6.01 \pm 1.174$ & $7.07 \pm 1.222$ & -2.727 & $0.006^{*}$ \\
\hline Left & $5.95 \pm 1.177$ & $6.91 \pm 0.985$ & -2.705 & $0.007^{*}$ \\
\hline
\end{tabular}

Mann-Whitney U test, ${ }^{*} \mathrm{p}<0.05$.

surrounding tissue. In a review by Al-Rawi et al., ${ }^{[21]}$ the shape and the size of mandibular condyle was suggested to change with trauma or endocrine disorders. In addition, resent researches highlighted that morphological changes could trigger intra-articular irregularities and dysfunctions.

The shape and the morphometry of mandibular condyle affect the functional properties of the TMJ. ${ }^{[2]}$ Yale et al. ${ }^{[2]}$ emphasized that the condylar shape shows wide range of variations and classified the shape of the mandibular condyle under four main types: flat, convex, angular, and round. The convex shape was reported to be the most frequent $(58.3 \%)$, followed by flat $(25.2 \%)$, angular $(11.6 \%)$ and round (3\%). The remainder was classified as miscellaneous $(1.9 \%) .^{[2]}$ Oliveria et al. ${ }^{[24]}$ and Wangai et al. ${ }^{[25]}$ supported that the convex type was more

Table 5

The correlation between muscle size and depth of the mandibular fossa.

\begin{tabular}{|c|c|c|c|c|c|c|}
\hline & & & \multicolumn{2}{|c|}{ TMD group } & \multicolumn{2}{|c|}{ Control group } \\
\hline & & & $r$ & $p$ & $r$ & $p$ \\
\hline \multirow[t]{4}{*}{ Masseter } & Length & Right & $0.63^{*}$ & 0.00 & $0.38^{+}$ & 0.04 \\
\hline & & Left & $0.78^{*}$ & 0.00 & $0.37^{\dagger}$ & 0.04 \\
\hline & Width & Right & 0.16 & 0.40 & $-0.43^{\dagger}$ & 0.02 \\
\hline & & Left & 0.25 & 0.19 & -0.33 & 0.08 \\
\hline \multirow[t]{4}{*}{ Superior LP } & Length & Right & 0.06 & 0.74 & $-0.47^{*}$ & 0.00 \\
\hline & & Left & -0.03 & 0.90 & $-0.42^{\dagger}$ & 0.02 \\
\hline & Width & Right & $0.40^{\dagger}$ & 0.03 & -0.35 & 0.06 \\
\hline & & Left & 0.15 & 0.44 & -0.31 & 0.10 \\
\hline \multirow[t]{4}{*}{ Inferior LP } & Length & Right & -0.09 & 0.65 & $-0.43^{\dagger}$ & 0.02 \\
\hline & & Left & -0.05 & 0.80 & $-0.41^{\dagger}$ & 0.03 \\
\hline & Width & Right & 0.34 & 0.07 & $-0.42^{\dagger}$ & 0.02 \\
\hline & & Left & 0.26 & 0.17 & $-0.51 *$ & 0.00 \\
\hline \multirow[t]{4}{*}{ MP } & Length & Right & 0.32 & 0.09 & $-0.45^{\dagger}$ & 0.01 \\
\hline & & Left & 0.29 & 0.13 & -0.34 & 0.06 \\
\hline & Width & Right & 0.25 & 0.19 & $-0.48^{*}$ & 0.00 \\
\hline & & Left & 0.20 & 0.30 & $-0.45^{\dagger}$ & 0.01 \\
\hline
\end{tabular}

*Spearman test; correlation is significant at the 0.01 level (2-tailed). ${ }^{+}$Correlation is significant at the 0.05 level (2-tailed). Inferior LP: inferior head of lateral pterygoid, MP: medial pterygoid; Superior LP: superior head of lateral pterygoid. 
Table 6

Pre- and post-treatment measurements $(\mathrm{mm})$ of mandibular movements between Groups A and B.

\begin{tabular}{|c|c|c|c|c|c|c|c|c|}
\hline & \multicolumn{4}{|c|}{ Group A } & \multicolumn{4}{|c|}{ Group B } \\
\hline & $\begin{array}{l}\text { Pre-treatment } \\
\text { mean } \pm S D\end{array}$ & $\begin{array}{l}\text { Post-treatment } \\
\text { mean } \pm S D\end{array}$ & $z$ & $\mathrm{p}$ & $\begin{array}{l}\text { Pre-treatment } \\
\text { mean } \pm S D\end{array}$ & $\begin{array}{l}\text { Post-treatment } \\
\text { mean } \pm S D\end{array}$ & $z$ & p \\
\hline Depression & $34 \pm 9.65$ & $40.55 \pm 8.60$ & -3.521 & $0.000 *$ & $37.87 \pm 10.58$ & $39.81 \pm 6.42$ & -0.754 & 0.451 \\
\hline Protrusion & $5.44 \pm 3.84$ & $8.33 \pm 3.47$ & -3.344 & $0.001 *$ & $6.12 \pm 3.44$ & $6.31 \pm 3.13$ & -0.318 & 0.751 \\
\hline RLD & $5.83 \pm 2.57$ & $8.66 \pm 1.68$ & -3419 & $0.001 *$ & $5.06 \pm 3.31$ & $5.18 \pm 2.76$ & -0.191 & 0.849 \\
\hline LLD & $5.27 \pm 3.10$ & $8.38 \pm 2.56$ & -3.417 & 0.001 * & $5.68 \pm 3.19$ & $5.93 \pm 2.76$ & -0.456 & 0.648 \\
\hline
\end{tabular}

Wilcoxon Test, ${ }^{*} \mathrm{p}<0.05$. LLD: left lateral deviation; RLD: right lateral deviation.

commonly seen as $41 \%$ and $80.2 \%$ of their cases respectively. Angular or flat type condyles was also revealed as the most common by some other studies. ${ }^{[26,27]}$ The present study showed that the flat type was more frequently found in healthy subjects (58.8\%) whereas the convex type in TMD patients (63.6\%). The rarest one was angular type that only encountered in case. There was no significant difference between two groups in terms of the shape of the condyle $(p>0.05)$. The morphology and morphometrical characteristics of the condyle in relation to the articular fossa have been shown to affect occlusal properties of the mandible. ${ }^{[25]}$ In the present study, we determined significant differences in depth of the mandibular fossa between TMD and healthy groups and it was significantly shallower in TMD group $(\mathrm{p}<0.05)$ (Table 2). Ballesteros et al. ${ }^{[28}$ studied 120 male cadavers and specified that depth of mandibular fossa changed with respect to age and occlusal variety. Their findings supported our results that indicated the mandibular fossa to get flatter in occlusal deformation. On the contrary, Sato et al.$^{[29]}$ revealed that depth of the mandibular fossa increases in anterior disc displacement but this result was not statistically significant.

Masticatory muscles are of other important anatomic structures in TMD. The size of the masticatory muscles, their cross-sectional areas and the characteristics of muscle fibers are adapted to their functions. ${ }^{[30]}$ Schellhas ${ }^{[19]}$ stated that the musculoskeletal system problems may cause hypertrophy/atrophy or asymmetry in length of masticatory muscles. Another study highlighted that changes in the size of masticatory muscles can reduce its strength and also may affect jaw movements. ${ }^{[3]}$ Also, our results supported that the length and width of the masticatory muscles significantly decreased in TMD patients resulting in muscle atrophy $(\mathrm{p}<0.05)$ (Table 2$)$. The atrophy of muscles may also be one of the reasons for limitations in jaw movements. Owing to limitation in jaw movements, masticatory muscles may not work in their normal physiological ranges and after that, atrophy would be an inevitable outcome in the long term.

In present study, we correlated the size of the masticatory muscles with the depth of mandibular fossa. There was a significant positive correlation in the control group but correlation was significantly decreased in the TMD group (Table 5). Faulkner et al. ${ }^{[3]}$ revealed that shallower mandibular fossa with pain can cause disruption of balance in joint loading. The correlations found in our study suggest that muscle atrophy may also cause a decrease in depth of mandibular fossa resulting in deterioration of range of mandibular motion that may lead to misbalance in joint loading in TMD patients. The optimum length of the skeletal muscle is regulated by the number of sarcomeres. ${ }^{[33]}$ Thus, when the muscle is held at a shortened length, due to muscle plasticity, the number of sarcomere units may decrease.

The oro-motor balance during chewing, breathing, speaking and swallowing is related with the functions of the jaw, the lips and the tongue. ${ }^{[33]}$ The most common complaint that causes the patient to refer to the physician in TMD is pain, and clinical outcome is the accompanying limitation in jaw movements. ${ }^{[2,14,27]}$ These two factors negatively affect the daily lives of individuals. Reducing pain and limitation are of the most important goals in treatment of TMD.$^{[6]}$ Perez et. al. ${ }^{[16]}$ reported a significant decrease in pain during rest and chewing, and increase in range of jaw movements after dry needling to lateral pterygoid muscle. Myorelaxation therapy and occlusal splints are declared as effective methods in reducing pain thus resulting increase in depression angle of mandible (maximum mouth opening) and increase in lateral movements of the jaw. ${ }^{[14,18]}$ Another study which applied manual therapy in addition to home exercises, emphasized reducing pain and increase in jaw movements. ${ }^{[17]}$ Likewise, present study showed a significant decrease in pain and increase in all mandibular movements in dry needling and mobilization groups $(\mathrm{p}<0.05)$. 
However, no significant change was detected in these parameters in the static splint group. These differences between treatment results can be attributed to myorelaxation effect of dry needling and mobilization. Because these methods are targeting directly to the muscles unlike splint. Also following up the appropriate usage of splint and knowing whether the given home exercises is done effectively as suggested or not is difficult and only rely on discourse of patients.

One of the limitations of this study was the unequal number of the females and males participated to this study. TMD prevalence is reported to be higher in females; similarly, the number of female participants was higher than males in our study. The size of the muscles in males differs from females and this may affect the mean results. Inadequate number of the participants is another limitation of our study; however, we suggest that our data is statistically reliable and reproducible.

\section{Conclusion}

In conclusion, temporomandibular components and associated structures showed statistically significant differences among the patients with TMD and healthy individuals. In TMD, the shape of the mandibular condyle does not seem to be related with the disorder since it can be of various types. However, the depth of the mandibular fossa was shallower and masticatory muscles were atrophic in TMD. Our results suggested that dry needling and mobilization, which directly target on the muscles, are more effective than occlusal splint and home exercises. We believe that this study will be useful to understand the anatomic differences or changes in TMJ caused by TMD.

\section{Conflict of Interest}

The author declare no potential conflicts of interest with respect to the research, authorship, and publication of this article.

\section{Author Contributions}

FD: concept, design, data processing, literature reviewing, analysis and interpretation, writing manuscript; AEÇ: concept, design, data processing, writing manuscript, proof reading; NA: concept, design, data collection and processing, analysis and interpretation; FÖ: concept, design, data collection and processing, analysis and interpretation, writing manuscript; BY: data collection and processing, analysis and interpretation, literature reviewing, writing manuscript; EDH: data collection and processing, analysis and interpretation, literature reviewing; ID: data collection and processing, analysis and interpretation.

\section{Ethics Approval}

The study was approved by the Mustafa Kemal University Clinical Research Ethics Committee (No: 4298783/050-41) and carried out in accordance with the Helsinki Declaration of Principles.

\section{Funding Statement}

The authors declare no financial support.

\section{References}

1. Schiffman E, Ohrbach R, Truelove E, Look J, Anderson G, Goulet JP, et al.; International RDC/TMD Consortium Network, International association for Dental Research; Orofacial Pain Special Interest Group, International Association for the Study of Pain. Diagnostic criteria for temporomandibular disorders (DC/TMD) for clinical and research applications: recommendations of the international RDC/TMD consortium network and orofacial pain special interest group. J Oral Facial Pain Headache 2014;28:6-27.

2. Davoudi A, Khaki H, Mohammadi I, Daneshmand M, Tamizifar A, Bigdelou M, Ansaripoor F. Is arthrocentesis of temporomandibular joint with corticosteroids beneficial? A systematic review. Med Oral Patol Oral Cir Bucal 2018;23:367-75.

3. Mathew AL, Sholapurkar AA, Pai KM. Condylar changes and its association with age, TMD, and dentition status: a cross-sectional study. Int J Dent 2011;2011:413639.

4. Van Bellinghen X, Idoux-Gillet Y, Pugliano M, Strub M, Bornert F, Clauss F, Schwinté P, Keller L, Benkirane-Jessel N, KuchlerBopp S, Lutz JC, Fioretti F. Temporomandibular joint regenerative medicine. Int J Mol Sci 2018;19:446.

5. Murphy MK, MacBarb RF, Wong ME, Athanasiou KA. Temporomandibular disorders: a review of etiology, clinical management, and tissue engineering strategies. Int J Oral Maxillofac Implants 2013;28:393-414.

6. Iwasaki LR, Liu H, Gonzalez YM, Marx DB, Nickel JC. Modeling of muscle forces in humans with and without temporomandibular joint disorders. Orthod Craniofac Res 2015;18 Suppl 1:170-9.

7. Paknahad M, Shahidi S, Iranpour S, Mirhadi S, Paknahad M. Cone-beam computed tomographic assessment of mandibular condylar position in patients with temporomandibular joint dysfunction and in healthy subjects. Int J Dent 2015;2015:301796.

8. Imanimoghaddam M, Madani AS, Mahdavi P, Bagherpour A, Darijani M, Ebrahimnejad H. Evaluation of condylar positions in patients with temporomandibular disorders: a cone-beam computed tomographic study. Imaging Sci Dent 2016;46:127-31.

9. Paknahad M, Shahidi S, Akhlaghian M, Abolvardi M. Is mandibular fossa morphology and articular eminence inclination associated with temporomandibular dysfunction? J Dent (Shiraz) 2016;17: 134-41.

10. Garip H, Tufekcioglu S, Kaya E. Changes in the temporomandibular joint disc and temporal and masseter muscles secondary to bruxism in Turkish patients. Saudi Med J 2018;39:81-5.

11. Ivorra-Carbonell L, Montiel-Company JM, Almerich-Silla JM, Paredes-Gallardo V, Bellot-Arcís C. Impact of functional mandibular advancement appliances on the temporomandibular joint-a systematic review. Med Oral Patol Oral Cir Bucal 2016;21: 565-72. 
12. Ucar M, Sarp Ü, Koca İ, Eroğlu S, Yetisgin A, Tutoglu A, Boyacı A. Effectiveness of a home exercise program in combination with ultrasound therapy for temporomandibular joint disorders. J Phys Ther Sci 2014;26:1847-9.

13. van Grootel RJ, Buchner R, Wismeijer D, van der Glas HW. Towards an optimal therapy strategy for myogenous TMD, physiotherapy compared with occlusal splint therapy in an RCT with therapy-and-patient-specific treatment durations. BMC Musculoskelet Disord 2017;18:76.

14. Gomes CA, El Hage Y, Amaral AP, Politti F, Biasotto-Gonzalez DA. Effects of massage therapy and occlusal splint therapy on electromyographic activity and the intensity of signs and symptoms in individuals with temporomandibular disorder and sleep bruxism: a randomized clinical trial. Chiropr Man Therap 2014;22:43.

15. Kuzmanovic Pficer J, Dodic S, Lazic V, Trajkovic G, Milic N, Milicic B. Occlusal stabilization splint for patients with temporomandibular disorders: meta-analysis of short and long term effects. PLoS One 2017;12:e0171296.

16. Gonzalez-Perez LM, Infante-Cossio P, Granados-Nunez MM, Urresti-Lopez FJ, Lopez-Martos R, Canela-Mendez PR. Deep dry needling of trigger points located in the lateral pterygoid muscle: efficacy and safety of treatment for management of myofascial pain and temporomandibular dysfunction. Med Oral Patol Oral Cir Bucal 2015;20:326-33.

17. Armijo-Olivo S, Pitance L, Singh V, Neto F, Thie N, Michelotti A. Effectiveness of manual therapy and therapeutic exercise for temporomandibular disorders: systematic review and meta-analysis. Phys Ther 2016;96:9-25.

18. Gawriołek K, Azer SS, Gawriołek M, Piotrowski PR. Mandibular function after myorelaxation therapy in temporomandibular disorders. Adv Med Sci 2015;60:6-12.

19. Schellhas KP. MR imaging of muscles of mastication. AJR Am J Roentgenol 1989;10:829-37.

20. Kai Y, Matsumoto K, Ejima K, Araki M, Yonehara Y, Honda K. Evaluation of the usefulness of magnetic resonance imaging in the assessment of the thickness of the roof of the glenoid fossa of the temporomandibular joint. Oral Surg Oral Med Oral Pathol Oral Radiol Endod 2011;112:508-14.

21. Al-Rawi NH, Uthman AT, Sodeify SM. Spatial analysis of mandibular condyles in patients with temporomandibular disor- ders and normal controls using cone beam computed tomography. Eur J Dent 2017;11:99-105.

22. Yale SH, Allison BD, Hauptfuehrer JD. An epidemiological assesment of mandibular condyle morphology. Oral Surg Oral Med Oral Pathol 1966;21:169-77.

23. Arnett GW, Milam SB, Gottesman L. Progressive mandibular retrusion-idiopathic condylar resorption. Part II. Am J Orthod Dentofacial Orthop 1996;110:117-27.

24. Oliveira-Santos C, Bernardo RT, Capelozza ALÁ. Mandibular condyle morphology on panoramic radiographs of asymptomatic temporomandibular joints. Int J Dent 2009;8:114-8.

25. Wangai L, Mandela P, Butt F, Ongeti K. Morphology of the mandibular condyle in a Kenyan population. Anatomy Journal of Africa 2013;2:70-9.

26. Matsumoto MAN, Bolognese AM. Bone morphology of the temporomandibular joint and its relation to dental occlusion. Braz Dent J 1995;6:115-22.

27. Oeberg T, Carlsson G, Fajers CM. The temporomandibular joint. A Morphologic study on a human autopsy material. Acta Odontol Scand 1971;29:349-84.

28. Ballesteros Acuña LE, Ramirez Aristeguieta LM, Munoz Mantilla G. Mandibular fossa depth variations: relation to age and dental state. Int J Morphol 2011;29:1189-94.

29. Sato S, Kawamura H, Motegi K, Motegi K, Takahashi K. Morphology of the mandibular fossa and the articular eminence in temporomandibular joints with anterior disc displacement. Int J Oral Maxillofac Surg 1996;25:236-8.

30. Goto TK, Yahagi M, Nakamura Y, Tokumori K, Langenbach GEJ, Yoshiura K. In vivo cross-sectional area of human jaw muscles varies with section location and jaw position. J Dent Res 2005;84:570-5.

31. Grünheid T, Langenbach GE, Korfage JA, Zentner A, Van Eijden TM. The adaptive response of jaw muscles to varying functional demands. Eur J Orthod 2009;31:596-612.

32. Faulkner MG, Hatcher DC, Hay A. A three-dimensional investigation of temporomandibular joint loading. J Biomech 1987;20: 997-1002.

33. Herring SW, Grimm AF, Grimm BR. Regulation of sarcomere number in skeletal muscle: a comparison of hypotheses. Muscle Nerve 1984;7:161-73.

Correspondence to: Fatma Duman, PhD

Department of Anatomy, Tayfur Ata Sökmen School of Medicine, Mustafa Kemal University, Alahan, 31060, Hatay, Turkey

Phone: +90 3262455114

e-mail: drfatmaduman@gmail.com

Conflict of interest statement: No conflicts declared.

This is an open access article distributed under the terms of the Creative Commons Attribution-NonCommercial-NoDerivs 4.0 Unported (CC BY-NCND4.0) Licence (http://creativecommons.org/licenses/by-nc-nd/4.0/) which permits unrestricted noncommercial use, distribution, and reproduction in any medium, provided the original work is properly cited. How to cite this article: Duman F, Çiçekçibaşı AE, Atçı N, Öztürk F, Yücekaya B, Doğru Hüzmeli E, Damlar İ. Morphological changes in temporomandibular joint dysfunction and effectiveness of different treatment methods. Anatomy 2020;14(2):102-110. 